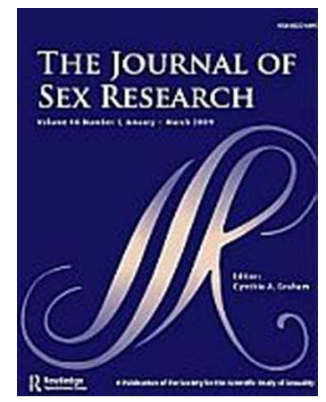

\title{
Predictors of prejudice against gays and lesbians in Jamaica
}

\begin{tabular}{|r|l|}
\hline Journal: & The Journal of Sex Research \\
\hline Manuscript ID: & $13-114$. R1 \\
\hline Manuscript Type: & Original Article \\
\hline Keywords: & $\begin{array}{l}\text { Antigay Prejudice, Cross-Cultural Comparison/Differences in Behavior, } \\
\text { Special Populations/Gay, lesbian, bisexual, Quantitative/Statistical /Survey, } \\
\text { Societal Attitudes }\end{array}$ \\
\hline
\end{tabular}




\begin{abstract}
Jamaica has earned an international reputation for strong anti-gay prejudice, incidents of antigay violence, and outspoken, anti-gay public figures. In recent years national and international gay rights groups have attempted to reduce prejudice against gays and lesbians in Jamaica. However, this work has thus far not been based on an empirical understanding of the predictors of Jamaican anti-gay bias, which is essential for developing effective prejudicereducing strategies. Using data collected in two large-scale national surveys in 2011 and 2012 $\left(\mathrm{N}_{2011}=997, \mathrm{~N}_{2012}=945\right)$, we investigated predictors of Jamaican anti-gay prejudice including age, gender, religious affiliation, education, income, and a preference for dancehall music. We also investigated changes in reported anti-gay bias between 2011 and 2012 after accounting for other predictors. All proposed variables predicted some aspect of anti-gay prejudice, though sometimes in unexpected ways. Male gender emerged as a particularly important predictor of anti-gay bias. We discuss the strengths and limitations of our design and the implications of our findings for prejudice-reduction strategies in Jamaica.
\end{abstract}

\title{
Word count: 6986
}

Keywords: GAY; PREJUDICE; JAMAICA; 
Though sexual prejudice is a serious global problem, Jamaica has earned an international reputation for particularly strong, pervasive, anti-gay prejudice. It has been called the "most homophobic place on earth" (Padgett, 2006, p. 1). Jamaican newspapers often describe "anti-gay murders and gay bashing incidents" (Gay lobby rebuked, 2008, p. 1), including the murder of Brian Williamson, one of Jamaica's most prominent and vocal gay rights activists. Reportedly, a crowd rejoiced over Williamson's mutilated body (Clunis, 2004a). Anti-gay attitudes are evident in the public discourse at all levels of society (Cowell \& Saunders, 2011): at international concerts, popular Jamaican performing artists have unapologetically performed songs that incited violence against gay men (Clunis, 2004b), and the (then) Prime Minister, the Right Honourable Bruce Golding, announced on international television that no homosexual could be a member of his parliament ("Homophobic silliness and a failure of leadership," 2008). Very little empirical research has investigated anti-gay prejudice in Jamaica (Charles, 2011; Cowell \& Saunders, 2011; Cowell, 2011). However, what little research exists supports anecdotal indications that this prejudice is both stronger (West \& Hewstone, 2012a), and more socially acceptable (West \& Hewstone, 2012b) in Jamaica than it is in other countries, including those in the Caribbean (Boxill, Lewis, Russell, \& Bailey, 2007).

In recent years, however, a number of changes have occurred. Jamaican gay-rights activists appear to be increasing in number, influence (Buckley, 2012) and willingness to openly criticize anti-gay behaviour (West, 2012). Some popular Jamaican performance artists have publicly apologized for past songs that encouraged anti-gay prejudice and violence (Campbell, 2012). Jamaica's current Prime Minister, the Right Honourable Portia SimpsonMilller, was nominated by Time Magazine as one of the world's 100 most influential persons, in part for being the first Jamaican head of state to publicly support equal treatment for gays in Jamaica (Wynter, 2012). 
Though Jamaican gay rights activists have made numerous efforts to engender social change, the conception and implementation of these interventions have thus far have not been based on empirical research investigating the predictors of Jamaican anti-gay prejudice. Thus, despite the most well-meaning or careful efforts, current strategies may not be the most effective means of bringing about these desired social changes. Worse still, they may be costly and ineffective, or even counter-effective, causing a backlash of anti-gay sentiment. The possibility of this backlash has been underscored by recent events including strong resistance from anti-gay lobbies that hope to prevent or reverse these shifts in public opinion (Buckley, 2012), and an attack on an allegedly gay student at a university in Kingston in which a mob chased him, calling for his death (Pearson, 2012). This research aims to fill some of the gaps in our understanding of Jamaican anti-gay prejudice by investigating its predictors as well as any evidence of changes in these attitudes over time (between 2011 and 2012).

\section{Predictors of Jamaican Sexual Prejudice}

Though no such research has previously been conducted in Jamaica, a well-established body of research from other countries (mostly the U.S.A.) has investigated the predictors of anti-gay bias. The principal findings in this area are derived from both experimental and cross-sectional data and have been summarized several times (Glenn \& Weaver, 1979; Herek \& Capitanio, 1995; Herek \& Glunt, 1993; Herek \& Gonzalez-Rivera, 2006; Herek, 1988, 2000; Irwin \& Thompson, 1978; Jensen, Gambles, \& Olsen, 1988; Schneider \& Lewis, 1984; Sherrod \& Nardi, 1998; Vincent, Parrott, \& Peterson, 2011; Whitley, 1990). The most reliable predictors of anti-gay prejudice are gender, age, education and religiosity, often measured by frequency of attendance at church services (e.g., Herek \& Gonzalez-Rivera, 2006). Heterosexual individuals are more likely to express negativity toward gays if they are older, less educated and more religious; we expect to find similar results in this research using a Jamaican sample.

Gender predicts anti-gay bias in multiple ways. Previous research has reliably found 
that male participants' attitudes toward gays were more negative than females' attitudes (e.g., Herek \& Gonzalez-Rivera 2006), and that male gender was a more important predictor of anti-gay bias than other demographic variables (e.g., Sherrod and Nardi 1998). Furthermore, most studies do not distinguish between attitudes toward lesbians and attitudes toward gay men (Herek, 2000), however, those that do reliably find both an effect of target gender and an interaction of participant and target gender. Not only do participants tend to report more prejudice against gay men than against lesbians, this effect is particularly strong for heterosexual men and may be absent in heterosexual women (Cuenot \& Fugita, 1982; Herek, 1988; Yarber \& Yee, 1983). In keeping with previous research we predict that male heterosexual participants will express more negativity toward gays than will female heterosexual participants and that all participants will report more bias against gay men, than against lesbians.

In addition to the aforementioned predictors, we also investigate the importance of variables more specific to the Jamaican context: income and dancehall music. Despite the severity of Jamaican anti-gay prejudice (Pearson, 2012; West \& Hewstone, 2012a), some commentators have suggested that the problem of Jamaican anti-homosexuality is primarily restricted to the "lower levels of society" and have denied "any serious bit of discrimination in the middle classes" (Williams, 2004, p. 1). Though socio-economic class incorporates many complex interwoven concepts and cannot be assessed by income alone, the available data sets only provided measures of education and income. Thus, in this research we investigated whether income predicted anti-gay bias when education was already accounted for.

Dancehall is one of the most popular musical forms in Jamaica, and has been widely exported around the world (Hickling, 2004; Hope, 2006; Pinnock, 2007). Important characteristics of dancehall include lively beats, an attitude of resistance to foreign and colonial powers and a "fundamental preoccupation with sex and sexuality" (Pinnock, 2007, p. 48). Dancehall is sometimes seen as policing the borders of Jamaican masculinity, 
encouraging heterosexuality and polygamy and discouraging cunnilingus, anal sex and homosexuality (Sharpe \& Pinto, 2006).

The anti-gay aspects of dancehall have recently attracted international attention. The careers of certain dancehall artists have been threatened or curtailed because their songs allegedly promote anti-gay violence, and call for the death of (particularly male) gays (Clunis, 2004b). Popular lyrics include, "Ful dem up a kappa shat . . . Chi-chi man fi ded an dats a fak [Pump them full of copper shots (bullets) . . . Gay men should die and that's a fact]" (Farquharson, 2005, p 109), and "Aal bati-man fi ded [All homosexuals must die]" (Chin, 1997, p. 128). Though some interpret these lyrics as frank incitements to murder (Clunis, 2004a), some Jamaican public figures have defend these lyrics as merely "metaphorical" or "lyrical": an expression of disapproval, rather than an actual call to murder (Salih, 2007, p. 1; see also Cooper, 2004). They further point out that no empirical research to date has investigated the relationship, if any, between dancehall music and negative behaviour toward gays and lesbians. As such claims that dancehall encourages negative anti-gay behaviour remain speculative. In an effort to address this gap we investigated the relationship between a preference for dancehall and negative behaviour toward gays and lesbians, particularly violent anti-social behaviour.

\section{Present Research}

This research is a re-analysis of two large-scale national surveys of attitudes toward same-sex relationships in Jamaica conducted by Professor Ian Boxill and his research team in 2011 and 2012 (Boxill et al., 2011, 2012). As is the case with most re-analyses, the data were not collected with this purpose in mind. Therefore, it was necessary to select items from the surveys that best suited the constructs we were trying to measure. For this reason, some of the scales may not be ideal. However, for each constructed scale we defined the measured construct, outlined similarities between the present scales and scales that are more widely used and provided evidence that the scales were internally reliable. Because two different 
populations were sampled a year apart rather than the same population at two time points, this is not a longitudinal study. Nonetheless, we also sought, tentatively, to determine whether or not the data reflected any shifts in attitudes from one year to the next, which is of particular interest given concerns of a backlash in anti-gay prejudice.

As with most research on anti-gay bias (see for example Herek, 2000), the majority of the questions in this research are about prejudice against gay people, without distinguishing between gay men and lesbians. However, a small subset of the questions does differentiate between attitudes toward gay men and attitudes toward lesbians. Hence, we have divided the analyses into two sections; the first looks at the predictors of general anti-gay attitudes, the second specifically investigates the role of participant and target gender.

\section{Method}

Participants and Recruitment. The data were obtained from two nationally representative samples of 1,007 and 1000 adults aged 18 and over in 2011 (489 males and 508 females, mean age $=37.64, \min =17, \max =84, \mathrm{SD}=13.19)$ and $2012(482$ males and 463 females, mean age $=35.02, \min =15, \max =99, \mathrm{SD}=13.46$ ) respectively. Some participants (10 in 2011 and 55 in 2012) were excluded from the final analyses due to missing basic demographic information (e.g., age, gender and sexuality). In both cases, the sample was drawn from 231 communities spread across Jamaica. Roughly $40 \%$ of these communities were located in the major urban centres of Kingston, St Andrew and St Catherine, 30\% in other towns, and the remainder in deep rural areas. Data for the 2011 survey were collected between October 2010 and January 2011, while data for the 2012 survey were collected between April and May 2012. All data were collected via paper and pencil, face to face interviews obtained by contacting respondents at home. In an effort to reduce social desirability biases in responses, data were collected in private by "mature female interviewers with significant interviewing experience" (Boxill et al., 2011, p. 11). Participants were offered no incentive. There was a small, but significant difference in age between the two groups; 
participants recruited in 2011 were older than participants recruited in 2012, $t(1869)=4.26, p$ $<.001, d=.20$. However, there were no significant differences in gender distribution (Fisher's exact test, $p=.41$ ).

Potential predictors of anti-gay bias. Participants indicated their gender $(1=$ male, 2 $=$ female $)$ and their age as a whole number between 0 and 100. Participants also indicated their highest level of education $(1=$ No formal education, $2=$ Primary/Prep school, $3=$ Some secondary education, 4 = Completed secondary education, $5=$ Vocational/Skills training, $6=$ University, 7 = Some professional training beyond university, $8=$ Graduate degree, e.g., MSc, $P h D)$, their monthly income in Jamaican dollars ${ }^{1}(1=$ Under $\$ 5,000,2=\$ 5,000$ to $\$ 19,999,3$ $=\$ 20,000$ to $\$ 49,999,4=\$ 50,000$ to $\$ 69,999,5=\$ 70,000$ to $\$ 89,999,6=\$ 90,000$ to $\$ 109,999,7=\$ 110,000$ to $\$ 129,999,8=\$ 130,000$ to $\$ 149,999,9=\$ 150,000$ to $\$ 169,999,10$ $=\$ 170,000$ to $\$ 189,999,11=\$ 190,000$ to $\$ 209,999,12=\$ 210,000$ and above), whether "dancehall [was] the kind of music [they] listen to the most" $(-1=n o, 1=y e s)$, and how often they attended church $(1=$ Less than once a year, $2=$ Every year, $3=2$ to 3 times a year, $4=$ Every month, $5=$ Every Week).

Measures of non (gender)-specific anti-gay bias. For each construct we selected items that were used in both the 2011 and 2012 versions of the questionnaire that best reflected what we wanted to measure. We selected 5 items to assess negative attitudes toward gay people. Three of these items assessed emotional reactions toward gay people similar to the widely-used semantic differential scale developed by Wright, Aron, McLaughlin-Volpe and Ropp (1997 also used by West \& Hewstone, 2012 to measure attitudes toward gay men in Jamaica); "I feel you can trust a person who is homosexual." (reversed), "It bothers me to see two homosexual people together in public", and "When I see a homosexual I think: 'What a waste'.". The other two items assessed judgements of homosexuality similar to the Attitudes Toward Gays scale developed by Herek (1988; also used by Turner, Crisp, \& Lambert, 2007); "Homosexuality is immoral.", "Homosexuality is a sin.". Together, these 5 items formed a 
reliable scale $(\alpha=.72)$, all items loaded onto a single factor, and all factor loadings were moderate to high $(.55<\lambda<.78)$.

To assess social distance from gay people we selected four items that addressed participants' willingness to permit gays to occupy different social roles. These are similar to the social distance items developed by Bogardus (1925), contempory versions of which are still being used (see Corrigan, Green, Lundin, Kubiak, \& Penn, 2001); "If I discovered a friend was homosexual I would end the friendship", "It matters to me whether my friends are homosexual or not", "It would upset me if I learned that a close friend was homosexual", "I think homosexuals should not work with children". These 4 items formed a reliable scale $(\alpha=$ $.80)$, all items loaded onto a single factor, and all factor loadings were high $(.67<\lambda<.87)$.

To assess opposition to gay rights we used four items that directly addressed the rights and treatment of gays in Jamaican society; "Marriage between homosexual individuals is acceptable." (reversed), "Society should recognize homosexuality as normal." (reversed), "Homosexual behaviour should be against the law.", and "Organizations which promote homosexual rights are unnecessary.". This scale did not attain the conventional level of reliability $(\alpha=.63)$. However we retained all items as item deletion did not result in a more reliable scale, all items loaded onto a single factor, and all factor loadings were moderate to high $(.60<\lambda<.74)$.

Finally, to assess self-reported negative behaviour toward gays we used five items with which participants indicated whether they generally behaved in specific negative ways toward gays. These were similar to the behavioural intentions scale developed by Tam, Hewstone, Kenworthy, and Cairns (2009; also used by West \& Bruckmüller, 2013) except that they assessed past behaviour rather than future behavioural intentions; "I have damaged property of a homosexual person", "I usually make derogatory remarks about homosexuals", "I make derogatory remarks like "faggot" or "batty man" to people I suspect are homosexual", "I tease and make jokes about homosexuals", "I avoid homosexuals". These 6 items formed a 
reliable scale $(\alpha=.77)$, all items loaded onto a single factor, and all factor loadings were moderate to high $(.40<\lambda<.87)$. Unless otherwise stated, participants responded to all items on 5-point Likert scales $(1=$ Strongly disagree, $5=$ Strongly agree $)$. All four scales are negative for clarity of presentation, however it is worth noting that some items in each scale were reversed, which reduced the tendency to respond similarly to all items. No combination of scales could be made into a single, internally reliable scale with items that loaded onto a single factor.

Measures of gender-specific anti-gay bias. Only six questions specified the gender of the gay target (i.e., these items specifically assessed attitudes toward either gay men or lesbians, rather than gay people of both genders). Furthermore these questions were only asked of participants in the 2011 sample, thus only those participants $\left(\mathrm{N}_{2011}=997\right)$ are included in these analyses. These participants responded to six items, three for each target gender: "I would feel comfortable working closely with a male / female homosexual" $(1=$ Strongly Agree, 5 = Strongly Disagree); "I would feel uncomfortable knowing that my son's male teacher / my daughter's female teacher was homosexual." $(1=$ Strongly Agree, $5=$ Strongly Disagree; reversed); and "Do you feel that male / female homosexuality is a moral issue?" ( 1 = Morally wrong, 3 = It depends on the situation, 5 = Not a moral issue; reversed). Neither of the two scales attained the conventional level of reliability (gay men, $\alpha=.35$; lesbians, $\alpha=.40$ ). However, correlations between items were reliably significant if modest (gay men, .142<r<.181, all $p<.001$; lesbians, .134 $<r<.223$, all $p<.001$ ), all items for each scale loaded onto a single factor, and all factor loadings were moderate to high (gay men, $.63<\lambda<.69$; lesbians $.59<\lambda<.73$ ). Thus, for each target gender (i.e., gay men vs. lesbians) we used the mean of three responses as our measure of gender-specific anti-gay bias $^{2}$, with higher values indicating more bias.

\section{Results}

Participants responded to all items on 5-point Likert scales (1 to 5) where higher 
scores indicated more negativity. Overall participants reported very negative attitudes toward gays $(M=4.00, S D=.74)$, high levels of social distance $(M=3.61, S D=1.00)$ and high levels of opposition to gay rights $(M=4.08, S D=.76)$. One-sample t-tests revealed that means for these three outcome measures were all above the midpoint of the scale (3), $26.54<$ $t<62.05$, all $p<.001$. The exception was the mean score for negative behaviour $(M=2.86$, $S D=.93)$, which fell below the midpoint of the scale, $t(1916)=6.42, p<.001$. Correlations between predictor and outcome variables can be seen in Table 1. This table is useful for ruling out multi-collinearity between items in that all correlations are low to moderate $(-.279<r<$ .652). However, the relationships presented in this correlation matrix should not be given too much weight as predictors are being considered without simultaneously controlling for the effects of other variables. To investigate these relationships we use regression analyses.

Predictors of non (gender)-specific anti-gay bias. We used regression analyses to investigate the effects of our proposed predictors on each of the 4 measures of anti-gay bias. Regression weights of all predictors can be seen in Table 2. We performed regression analyses using all predictor variables simultaneously (i.e., gender, age, education, income, dancehall music, religiosity, and year) to predict each outcome variable (i.e., attitudes, social distance, support for gay rights and negative behaviours), so that each predictor is considered while taking all others into account. Though it would interesting to investigate how our four outcome variables related to each other, that was not the focus of this research. Our focus was to investigate the variables that best predicted anti-gay bias when other predictors were taken into account. Graphs of all predictors and their relative strengths are shown in Figures 1 - 4.

Negative attitudes. Female participants reported less negative attitudes toward gays ( $\beta$ $=-.14, p<.001)$, as did more educated participants $(\beta=-.11, p=.001)$ and participants with higher incomes $(\beta=-.087, p=.012)$. A preference for dancehall music predicted more negative attitudes toward gays $(\beta=.078, p=.009)$, as did religiosity $(\beta=.12, p<.001)$. Age did not predict negative attitudes $(\beta=.034, p=.25)$, nor did the year in which the survey was 
conducted $(\beta=.033, p=.23)$.

Social distance. Female participants reported less social distance toward gays $(\beta=$ $-.34, p<.001)$, as did more educated participants $(\beta=-.11, p=.001)$ and participants with higher incomes $(\beta=-.099, p=.003)$. A preference for dancehall music predicted more social distance toward gays $(\beta=.074, p=.009)$, as did religiosity $(\beta=.064, p=.024)$. Age did not predict social distance $(\beta=.006, p=.82)$. However, participants reported less social distance in 2012 than in $2011(\beta=-.07, p=.009)$.

Opposition to gay rights. Female participants reported less opposition to gay rights ( $\beta$ $=-.13, p<.001)$. However, neither education $(\beta=-.033, p=.35)$ nor income $(\beta=-.067, p=$ .054) predicted opposition to gay rights. A preference for dancehall music predicted more opposition to gay rights $(\beta=.079, p=.006)$, as did religiosity $(\beta=.068, p=.024)$ and age $(\beta$ $=.061, p=.042)$. However, opposition to gay rights did not differ according to year $(\beta=.04$, $p=.21)$

Negative behaviours. Female participants reported less negative behaviour toward gays $(\beta=-.28, p<.001)$, as did more educated participants $(\beta=-.14, p<.001)$ and participants with higher incomes $(\beta=-.11, p=.001)$. A preference for dancehall music predicted more negative behaviour toward gays $(\beta=.063, p=.023)$. However, both religiosity $(\beta=-.063, p=.025)$ and age $(\beta=-.075, p=.007)$ predicted less negative behaviour toward gays. Participants also reported less negative behaviour in 2012 than in $2011(\beta=-.096, p<.001)$.

Gender as a predictor of anti-gay attitudes. In line with previous research we further examined the role of gender by investigating attitudes toward gay men and lesbians separately. We investigated the effects of participant gender and target gender on anti-gay bias with a 2 (Participant Gender: Male vs. Female) x 2 (Target Gender: Gay Men vs. Lesbians) analysis of variance with repeated measures on the second factor, and bonferonni- 
adjusted post hoc comparisons. We found a small but significant effect of participant gender $F$ $(1,994)=4.49, p=.03, \eta_{p}{ }^{2}=.004 ;$ overall, males reported more anti-gay bias $(M=4.05)$ than did females $(M=3.96)$. We also found a significant effect of target gender $F(1,994)=$ 89.01, $p<.001, \eta_{p}{ }^{2}=.082$; overall, all participants reported more bias against gay men $(M=$ 4.12) than against lesbians $(M=3.89)$.

There was also a significant interaction of participant gender and target gender $F$ (1, $994)=91.97, p<.001, \eta_{p}{ }^{2}=.085$. Compared to females, males reported more prejudice against gay men $(M=4.30$ vs. $M=3.96, p<.001)$ but less prejudice against lesbians $(M=$ 3.81 vs. $M=3.97, p=.003$ ). Males also reported more prejudice against gay men than against lesbians $(M=4.30$ vs. $M=3.81, p<.001)$, but females did not report more prejudice against gay men than against lesbians $(M=3.96$ vs. $M=3.97, p=.91)$, see Figure 1.

In sum, all of our proposed predictors were associated with some aspect of anti-gay bias, but not all these relationships were in line with previous research. Female participants reported less negative attitudes, less social distance, less opposition to gay rights and less negative behaviour. More education and higher income predicted less negative attitudes, less social distance and less negative behaviour toward gays. A preference for dancehall music predicted more negative attitudes, more social distance, more opposition to gay rights and more negative behaviour. In line with prior research, religiosity predicted more negative attitudes, more social distance and more opposition to gay rights. However, religiosity also predicted less negative behaviour. In contrast with prior research, age did not did not predict either attitudes or social distance, and predicted less negative behaviour. In line with prior research age did predict more opposition to gay rights. Only gender and dancehall music predicted all four outcome variables consistently and male gender was consistently the strongest predictor of anti-gay bias. Furthermore, we found that participants reported more bias against gay men than against lesbians and that this difference was driven by heterosexual males' greater prejudice against gay men. Finally, we found no evidence of a recent backlash 
of anti-gay attitudes. On the contrary, when all other measured predictors were taken into account, participants in 2012 reported less social distance and negative behaviour toward gays than did participants in 2011.

\section{Discussion}

Jamaican prejudice against gay men and lesbians has been the subject of unfavourable comparisons to other western democratic societies and even to its neighbours in the Caribbean (Boxill et al., 2007; West \& Hewstone, 2012a). However, while numerous reports attest to the severity and ubiquity of anti-gay prejudice in Jamaica, almost no empirical research investigates this prejudice, its predictors, or any means of reducing it. Our research aimed to address this gap by investigating a number of potential predictors of anti-gay prejudice including some that have been explored in previous research and others that are specific to the Jamaican context.

We found that male gender was the strongest predictor of anti-gay prejudice, both in the sense that male participants expressed more prejudice and that more prejudice was expressed toward gay men than toward lesbians. More education and a higher income reliably predicted less anti-gay prejudice, while preference for dancehall music reliably predicted more. Age did not reliably predict anti-gay prejudice and predicted both more opposition to gay rights and less negative behaviour toward gays. Interestingly, religiosity generally predicted more anti-gay prejudice, but also predicted less negative behaviour toward gays. Below we discuss our findings in terms of research design, strengths and limitations, similarities with and differences between our findings and previous literature, and implications for managing anti-gay prejudice in Jamaica.

\section{Research Design and Results}

This research takes advantage of the rare incidence of two nation-wide surveys of responses to gay men and lesbians carried out during the years 2011 and 2012. Though similar research has been conducted in other societies, this is the first of its kind to be 
conducted in Jamaica. As such it provides much needed information to an underserved community. Strengths of this design include using large, nationally representative, nonstudent participant samples, which permit more confidence in the external validity of our findings than would the more frequently used, smaller, student samples (Henrich, Heine, \& Norenzayan, 2010).

In this research we focused primarily on main effects and found that all of our proposed predictors were associated with anti-gay bias in some way. The only interaction we explored was that between participant and target gender. We acknowledge that a number of other interactions could have been explored using these data. For example, some Jamaican commenters have suggested an interaction between male gender and dancehall music, specifically that males may be more susceptible to some of the negative, anti-gay messages in this music than females are (see West, 2010). However, with seven predictors and four outcome variables, there were hundreds of potential interactions to explore, which would increase the risk of Type I errors. Thus, we encourage future researchers, with specific theoretical grounding, to explore specific interactions in this population, in order to deepen our knowledge of Jamaican anti-gay prejudice.

Future research is needed to confirm causal directions. Nonetheless, these findings have important implications for improving gay rights in Jamaica. Some contemporary pro-gay activists work to challenge the idea that homosexuality is sinful or evil, though these efforts are resisted by the religious majority (Buckley, 2012; "Gay lobby rebuked," 2008). Our findings suggest that other strategies, such as increasing education and the general standard of living, may also be effective in Jamaica, as they tend to be internationally. There are also potential interventions more specific to the Jamaican context, such as addressing the content of dancehall music and the current ideal of masculinity. For example, it has been suggested that Jamaican masculinity has become overly focused on toughness and anti-femininity (Chevannes, 2001; West, 2010; see Thompson \& Pleck, 1986 for a discussion of masculine 
ideals). The popularity of dancehall could be used to promote more status- and responsibilitydriven ideals of masculinity, which could decrease anti-gay prejudice.

A limitation of this research is that these data were not designed for this purpose. Consequently, our scales are made of selected variables, rather than of items used in prior, established research. We have dealt with this issue as best we could by clearly identifying the constructs of interest, identifying similarities between our items and those used in prior research, and by applying high standards of internal reliability. Nonetheless, future research could build on this research with the use of these established scales. A related limitation is that some important constructs have not been included in this research because they were not measured in the original interviews. For example, intergroup contact, one of the best predictors of (less) prejudice (Pettigrew \& Tropp, 2006) including anti-gay prejudice (Herek \& Glunt, 1993), was not included in this research. Contact should certainly be included in future research of this nature. However, while this research is not an exhaustive list of the most important predictors of anti-gay prejudice in Jamaica, we nonetheless managed to investigate several key predictors identified by prior research in a new cultural environment.

Efforts were made to reduce social desirability biases in responses. Nonetheless we acknowledge that some response biases may have remained. This concern could be viewed a number of ways. In most research of this nature, anonymity permits participants to express more negative attitudes than they would express publicly, due to social norms about egalitarianism. Thus the face-to-face interviews may have reduced negativity toward gays and lesbians in our samples. However, this seems unlikely, as responses to both gays and lesbians were generally very negative. A contrasting possibility is that the face-to-face interviews could have encouraged more negative responses due to the Jamaican cultural norm of negativity toward gays and lesbians (West \& Hewstone, 2012b). At present, these data offer no means of testing whether either of these effects occurred. Furthermore, there is no indication that this affected the relationships between our proposed predictors and reported 
anti-gay bias. However, the different predictors of public vs. private and implicit vs. explicit anti-gay prejudice in Jamaica are worthy of investigation, and could be tackled in future research.

Perhaps the most serious limitation of this research is its cross-sectional, correlational design, which prohibits the testing of causal relationships between our variables. In other words, though we found that a preference for dancehall music predicted more anti-gay prejudice, it could be that higher prejudice leads to a preference for dancehall or that some other, unnamed factor predicts both. We acknowledge this limitation, though we point out that this is a limitation of all correlational research. Furthermore, while this research cannot offer a definitive test of causes of anti-gay prejudice in Jamaica, it nonetheless establishes a foundation for subsequent research, and highlights possible areas of fruitful future investigation. Subsequent experimental and longitudinal research could be used to clarify these relationships. Qualitative research, of which there are already good examples in Jamaica (e.g., Cowell \& Saunders, 2011) could also be used to enhance the understanding of the roots of Jamaican anti-gay sentiment, and suggest other possible causes to investigate quantitatively.

\section{Similarities and Differences with Prior Research}

Most of our findings align with those of previous research including research conducted in Jamaica (Cowell, 2011). As in prior research, participants were less likely to express prejudice against gays if they were female, more educated and had higher incomes, and if they were thinking about lesbians, rather than gay men. While the absolute differences between males' and females' anti-gay prejudice scores were small, it is worth noting that mean scores ranged from high to very high, with very little variation (in line with public responses to gays and media reports of gay beatings, bashings and killings), making such differences harder to detect.

Dancehall music, popular with young Jamaicans and international audiences, is a 
variable unique to this context. Though dancehall lyrics sometimes encourage anti-gay violence and murder (Chin, 1997), and though it has been suggested that dancehall music can increase prejudice against gays, in particular gay men (Pinnock, 2007; Saunders, 2003), this is the first empirical research to show an association between dancehall and anti-gay prejudice, including negative behaviours. Though more research is required to verify whether dancehall causes more anti-gay prejudice, this is nonetheless an important first step.

In contrast with previous research (e.g, Glenn \& Weaver, 1979; Herek \& Capitanio, 1995), age did not consistently predict anti-gay prejudice and even predicted less negative anti-gay behaviour. Thus, we found no evidence of a general softening of attitudes toward gay people over time. However, we also found no evidence of a backlash of anti-gay sentiment in response to recent gay rights activism. On the contrary, though we found no differences in anti-gay attitudes or in opposition to gay rights, participants in 2012 reported less social distance and less negative behaviour toward gays than did participants in 2011.

Our findings concerning religion also appear to be at odds with prior research. Like most research, we found that religiosity predicted more prejudice in terms of more negative attitudes, more social distance and more opposition to gay rights (Whitley, 2009). However, we also found that religiosity predicted less negative behaviour toward gays. Though this may seem contradictory, it is in line with the publicly espoused value of "love the sinner but hate the sin" and similar findings have been found in prior research (Mak \& Tsang, 2008, p 379). Though subsequent research should investigate this further, this current study suggests that different interventions may be maximally effective depending on the targets of the intervention (e.g., religious vs. non-religious Jamaicans) and the desired goal of the intervention (e.g., reducing negative behaviours vs. increasing support for gay rights).

\section{Conclusions}

This research investigates whether and how a number of variables including gender, education, income, dancehall music, religiosity and age, predict anti-gay prejudice in Jamaica. 
These findings hold important implications for social policy and gay activism in Jamaica. They reveal widespread, very negative responses to gay people in Jamaica, suggesting a relatively severe and intractable social problem, unlikely to be solved in the near future. However, they also suggest avenues by which change can be achieved. Though this research cannot imply causal relationships, future research and interventions could investigate the effects of altered perceptions of masculinity, increased education and income, and reduced or modified influence of dancehall music and religion. This is unlikely to be easy, given the severity and openness of Jamaican anti-gay prejudice, the entrenched hetero-normative values and the apparent stability of anti-gay sentiment (Cowell \& Saunders, 2011). However, this research offers important insights into strategies for creating a more egalitarian Jamaican society, as the more we know about the causes and predictors of anti-gay prejudice in Jamaica, the more effective prejudice-reducing strategies are likely to be. 


\section{References}

Bogardus, E. S. (1925). Measuring social distances. Journal of Applied Sociology, 9, 299 308.

Boxill, I., Galbraith, E., Mitchell, R., Russell, R., Johnson, S., \& Waller, L. (2012). National survey of attitudes and perceptions of Jamaicans towards same sex relationships: A follow-up study. Kingston, Jamaica. Retrieved from http://www.aidsfreeworld.org/RSS/ /media/Files/Homophobia/Jamaica National Survey on Homophobia.pdf

Boxill, I., Lewis, B., Russell, R., \& Bailey, A. (2007). The political culture of democracy in Jamaica: 2006. Nashville, TN.: Vanderbuilt University.

Boxill, I., Martin, J., Russell, R., Waller, L., Meikle, T., \& Mitchell, R. (2011). National survey of attitudes and perceptions of Jamaicans toward same sex relationships (pp. 1 51). Kingston, Jamaica. Retrieved from http://www.aidsfreeworld.org/OurIssues/Homophobia/ /media/Files/Homophobia/NATIONAL SURVEY OF ATTITUDES AND PERCEPTIONS OF JAMAICANS TOWARDS SAME SEX RELATIONSHIPS.pdf

Buckley, B. (2012, May 20). Balancing the gay-rights debate. The Jamaica Gleaner.

Campbell, H. (2012, May 25). "Beenie was brave" - Festival promoter lauds deejay. Jamaica Observer.

Charles, C. (2011). Representations of Homosexuality in Jamaica. Social and Economic Studies, 60(1), 3-30.

Chevannes, B. (2001). Learning to be a man: Culture, socialisation and gender identity in five Caribbean communities. Kingston, Jamaica: The University of the West Indies Press.

Chin, T. (1997). “ Bullers” and“" Battymen”: Contesting Homophobia in Black Popular Culture and Contemporary Caribbean Literature. Callaloo, 20(1), 127-141.

Clunis, A. (2004a, June 13). OUTRAGED!-British gays use Brian Williamson's death to push agenda. The Jamaica Gleaner, pp. 19-20.

Clunis, A. (2004b, June 27). London pressures dancehall stars. The Jamaica Gleaner, Retrieved from http://www.jamaica-gleaner.com/gleaner/20040627/lead/lead2.html

Cooper, C. (2004). Sound clash: Jamaican dancehall culture at large. New York: Palgrave McMillan.

Corrigan, P. W., Green, A., Lundin, R., Kubiak, M. A., \& Penn, D. L. (2001). Familiarity with and social distance from people who have serious mental illness. Psychiatric Services (Washington, D.C.), 52(7), 953-8. 
Cowell, N. M. (2011). Public Discourse, Popular Culture and Attitudes towards Homosexuals in Jamaica. . Social and Economic Studies, 31-60.

Cowell, N. M., \& Saunders, T. S. (2011). Exploring heteronormativity in the public discourse of Jamaican legislators. Sexuality \& Culture, 15, 315 - 331.

Cuenot, R. G., \& Fugita, S. S. (1982). Perceived homosexuality: Measuring heterosexual attitudinal and nonverbal reactions. Personality and Social Psychology Bulletin, 8(1), $100-106$.

Farquharson, J. T. (2005). Fiya-bon: The socio-pragmatics of homophobia in Jamaican (Dancehall) culture. In S. Muhleisen \& B. Migge (Eds.), Politeness and face in Caribbean Creoles (pp. 101 - 118). Amsterdam, The Netherlands: Blackwell.

Gay lobby rebuked - Church says won't accept homosexual lifestyle in Jamaica. (2008).The Jamaica Gleaner. Retrieved from http://www.jamaicagleaner.com/gleaner/20080218/lead/lead1.html

Glenn, N. D., \& Weaver, C. N. (1979). Attitudes toward premarital, extramarital, and homosexual relations in the US in the 1970s. Journal of Sex Research, 15(2), $108-118$.

Henrich, J., Heine, S. J., \& Norenzayan, A. (2010). The weirdest people in the world? The Behavioral and Brain Sciences, 33(2-3), 61-83

Herek, G. M. (1988). Heterosexuals' attitudes toward lesbians and gay men: Correlates and gender differences. Journal of Sex Research, 25(4), 451 - 477.

Herek, G. M. (2000). The Psychology of Sexual Prejudice. Current Directions in Psychological Science, 9(1), 19-22.

Herek, G. M., \& Capitanio, J. P. (1995). Black heterosexuals' attitudes toward lesbians and gay men in the United States. Journal of Sex Research, 32(2), 95 - 105.

Herek, G. M., \& Glunt, E. (1993). Interpersonal contact and heterosexuals' attitudes toward gay men: Results from a national survey. Journal of Sex Research, 30(3), 239-244.

Herek, G. M., \& Gonzalez-Rivera, M. (2006). Attitudes toward homosexuality among US residents of Mexican Descent. Journal of Sex Research, 43(2), 122 - 135.

Hickling, F. W. (2004). From Explanitations and Madnificent Irations to de Culcha Clash. Interventions: International Journal of Postcolonial Studies, 6(1), 45 - 66.

Homophobic silliness and a failure of leadership. (2008, May 22).The Jamaica Gleaner. Retrieved from http://www.jamaica-gleaner.com/gleaner/20080522/ cleisure/cleisure $1 . h t m l$

Hope, D. P. (2006). Passa passa : Interrogating cultural hybridities in Jamaican dancehall. Small Axe, 21(3), 125-139.

Irwin, P., \& Thompson, N. L. (1978). Acceptance of the rights of homosexuals: A social profile. Journal of Homosexuality, 3(2), 107 - 120. 
Jensen, L., Gambles, D., \& Olsen, J. (1988). Attitudes Toward Homosexuality: a Cross Cultural Analysis of Predictors. International Journal of Social Psychiatry, 34(1), 47-57.

Mak, H. K., \& Tsang, J. A. (2008). Separating the "sinner" from the "sin": Religious orientation and prejudiced behavior toward sexual orientation and promiscuous sex. Journal for the Scientific Study of Religion, 47, 379-392.

Padgett, T. (2006, April). The most homophobic place on Earth? Time, 1. Retrieved from http://www.time.com/time/world/article/0,8599,1182991,00.html

Pearson, D. (2012, November 11). Christian ethics and the UTech beating. Jamaica Gleaner. Retrieved from http://jamaica-gleaner.com/gleaner/20121111/cleisure/cleisure5.html

Pettigrew, T., \& Tropp, L. (2006). A Meta-Analytic Test of Intergroup Contact Theory. Journal of Personality and Social Psychology, 90(5), 751-783.

Pinnock, A. M. N. (2007). " A ghetto education is basic ": (Jamaican ) Dancehall masculinities as counter-culture. Journal of Pan African Studies, 1(9), 47-84.

Salih, S. (2007). "Our people know the difference, black is a race, jew is a religion, $\mathrm{f}^{*} \mathrm{~g}{ }^{* *}$ tism is a sin". Wasafiri, 22(1), $1-5$.

Saunders, P. J. (2003). Is Not Everything Good to Eat, Good to Talk: Sexual Economy and Dancehall Music in the Global Marketplace. Small Axe: A Caribbean Journal of Criticism, 13(March 2003), 95-115.

Schneider, W., \& Lewis, I. A. (1984). The straight story on homosexuality and gay rights. Public Opinion, 7(1), 16- 20.

Sharpe, J., \& Pinto, S. (2006). The sweetest taboo: Studies of caribbean sexualities: A review essay. Signs: Journal of Women in Culture and Society, 32(1), 247 - 274.

Sherrod, D., \& Nardi, P. M. (1998). Homophobia in the courtroom: An assessment of biases against gay men and lesbians in a multiethnic sample of potential jurors. Psychological Perspectives on Lesbian and Gay Issues, 4, 24 - 38.

Tam, T., Hewstone, M., Kenworthy, J., \& Cairns, E. (2009). Intergroup trust in Northern Ireland. Personality and Social Psychology Bulletin, 35(1), 45-59.

Thompson, E. H., \& Pleck, J. H. (1986). The Structure of Male Role Norms. American Behavioral Scientist, 29(5), 531-543.

Turner, R. N., Crisp, R. J., \& Lambert, E. (2007). Imagining Intergroup Contact Can Improve Intergroup Attitudes. Group Processes \& Intergroup Relations, 10(4), 427-441.

Vincent, W., Parrott, D. J., \& Peterson, J. L. (2011). Effects of Traditional Gender Role Norms and Religious Fundamentalism on Self-Identified Heterosexual Men's Attitudes, Anger, and Aggression Toward Gay Men and Lesbians. Psychology of men \& masculinity, 12(4), 383-400. 
West, K. (2010, March 21). Jamaican masculinity: Construction and consequences. The Jamaica Gleaner. Retrieved from http://jamaicagleaner.com/gleaner/20100321/lead/lead9.html

West, K. (2012, October 14). Out of Many, One People. The Jamaica Observer. Kingston, Jamaica. Retrieved from http://www.jamaicaobserver.com/columns/Out-of-many--onepeople_12732617

West, K., \& Bruckmüller, S. (2013). Nice and easy does it: How perceptual fluency moderates the effectiveness of imagined contact. Journal of Experimental Social Psychology, 49, $254-262$.

West, K., \& Hewstone, M. (2012a). Culture and contact in the promotion and reduction of anti-gay prejudice: Evidence from Jamaica and Britain. Journal of Homosexuality, 59(1), $44-66$.

West, K., \& Hewstone, M. (2012b). Relatively socially acceptable prejudice within and between societies. Journal of Community \& Applied Social Psychology, 22, 269-282.

Whitley, B. E. (1990). The Relationship of Heterosexuals' Attributions for the Causes of Homosexuality to Attitudes Toward Lesbians and Gay Men. Personality and Social Psychology Bulletin, 16(2), 369-377.

Whitley, B. E. (2009). Religiosity and Attitudes Toward Lesbians and Gay Men: A MetaAnalysis. International Journal for the Psychology of Religion, 19(1), 21-38.

Williams, P. (2004, December 5). The gay debate. The Jamaica Observer. Kingston, Jamaica. Retrieved from http://www.glapn.org/sodomylaws/world/jamaica/janews036.htm

Wright, S. C., Aron, A., McLaughlin-Volpe, T., \& Ropp, S. A. (1997). The extended contact effect: Knowledge of cross-group friendships and prejudice. Journal of Personality and Social Psychology, 73(1), 73 - 90.

Wynter, R. (2012, April 29). PM basks in glory . . . But is she tough enough? The Jamaica Gleaner.

Yarber, W. L., \& Yee, B. (1983). Heterosexuals' attitudes toward lesbianism and male homosexuality: Their affective orientation toward sexuality and sex guilt. Journal of American College Health, 31(5), 203-208. 
Tables

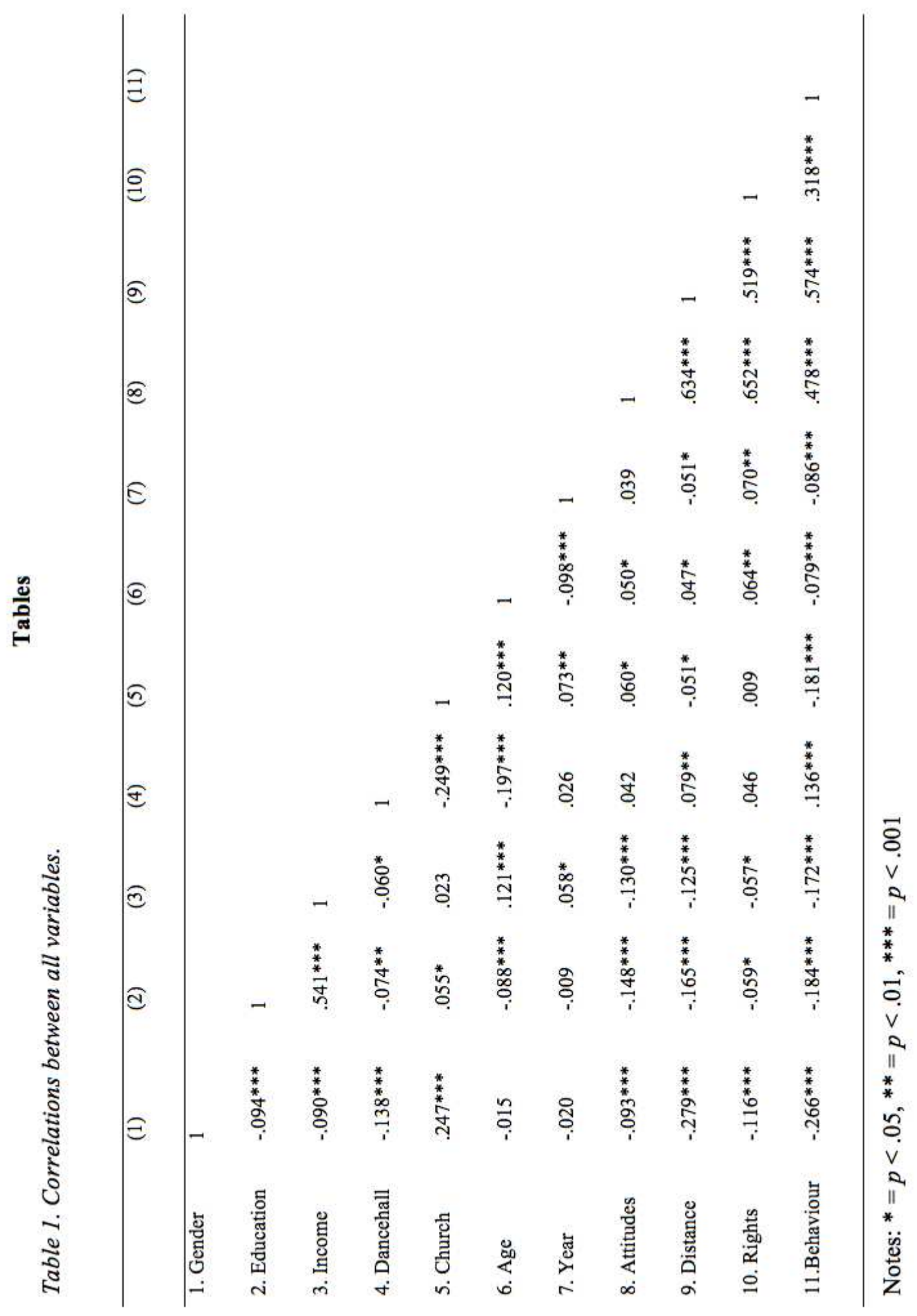


Table 2. Beta weights of predictor variables on measures of anti-gay bias.

\begin{tabular}{lllll}
\hline & Negative & Social & Opposition to & Negative \\
& Attitudes & Distance & Rights & Behaviours \\
& & & & \\
\hline Female Gender & $-.136^{* * *}$ & $-.336^{* * *}$ & $-.128^{* * *}$ & $-.282^{* * *}$ \\
Education & $-.111^{* *}$ & $-.105^{* *}$ & -.033 & $-.135^{* * *}$ \\
Income & $-.087^{*}$ & $-.099^{* *}$ & -.067 & $-.105^{* *}$ \\
Dancehall Music & $.078^{* *}$ & $.074^{* *}$ & $.079^{* *}$ & $.063^{*}$ \\
Religiosity & $.119^{* * *}$ & $.064^{*}$ & $.068^{*}$ & $-.063^{*}$ \\
Age & .034 & .006 & $.061^{*}$ & $-.075^{* *}$ \\
Year & .033 & $-.070^{* *}$ & .036 & $-.096^{* * *}$ \\
\hline
\end{tabular}

Notes: Standardized coefficients shown. $*=p<.05, * *=p<.01, * * *=p<.001$ 


\section{Figure Captions}

Figure 1: Predictors of negative attitudes toward gays.

Figure 2: Predictors of social distance from gays.

Figure 3: Predictors of opposition to gay rights.

Figure 4: Predictors of negative behaviours against gays.

Figure 5: Anti-gay prejudice according to participant and target gender. Bar graphs represent mean difference scores and standard error of the mean. 


\section{Figures}

Figure 1

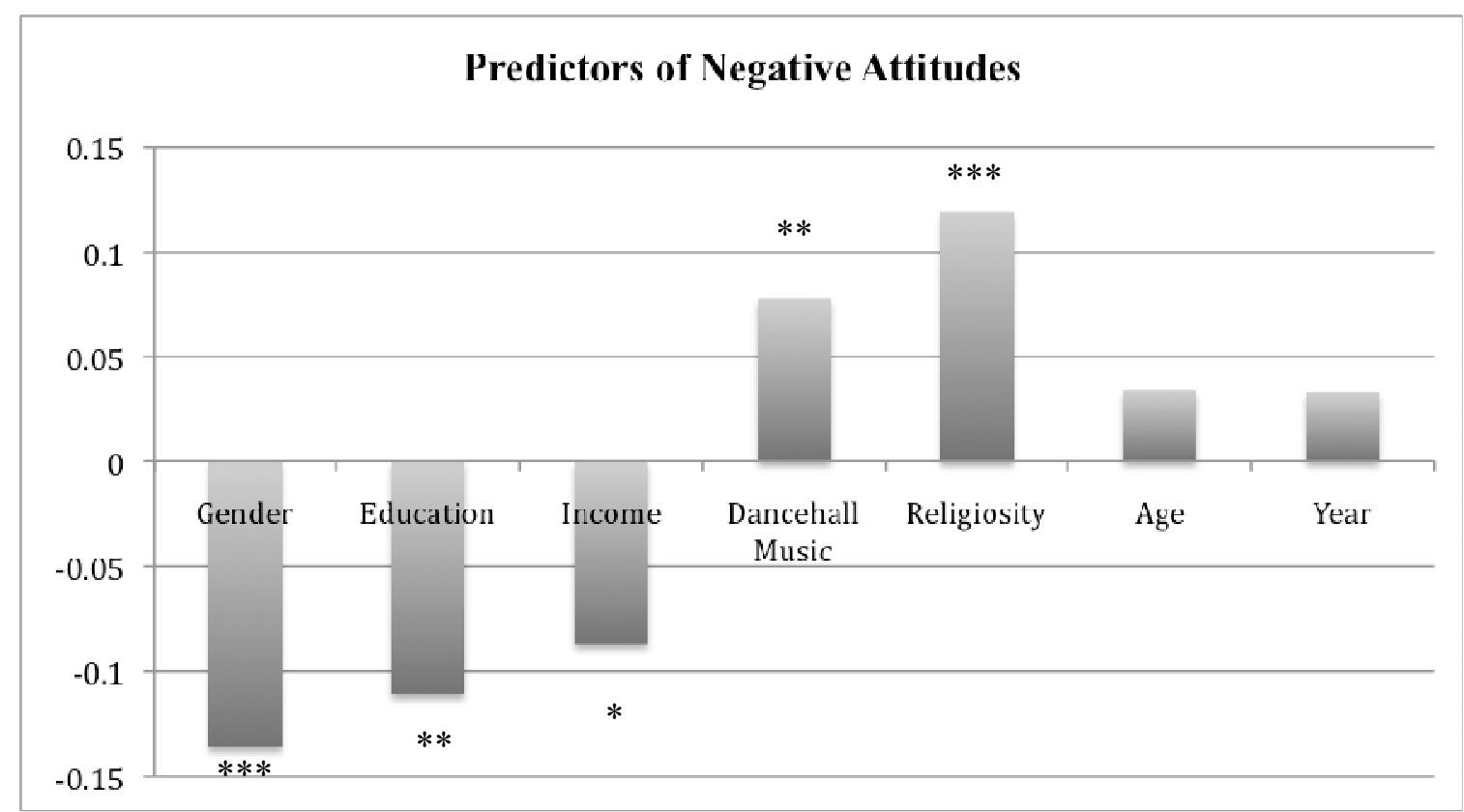

Figure 2

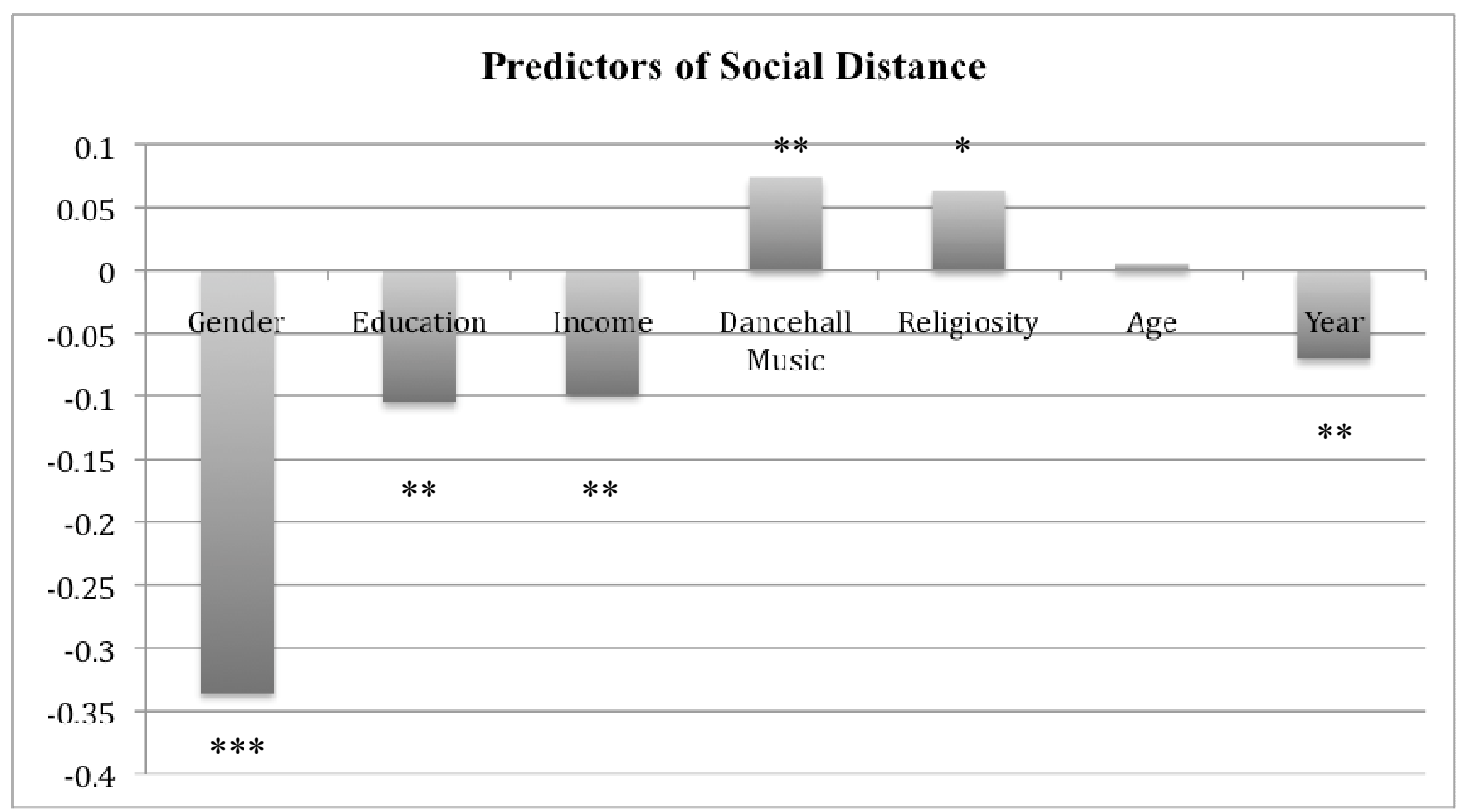


Figure 3

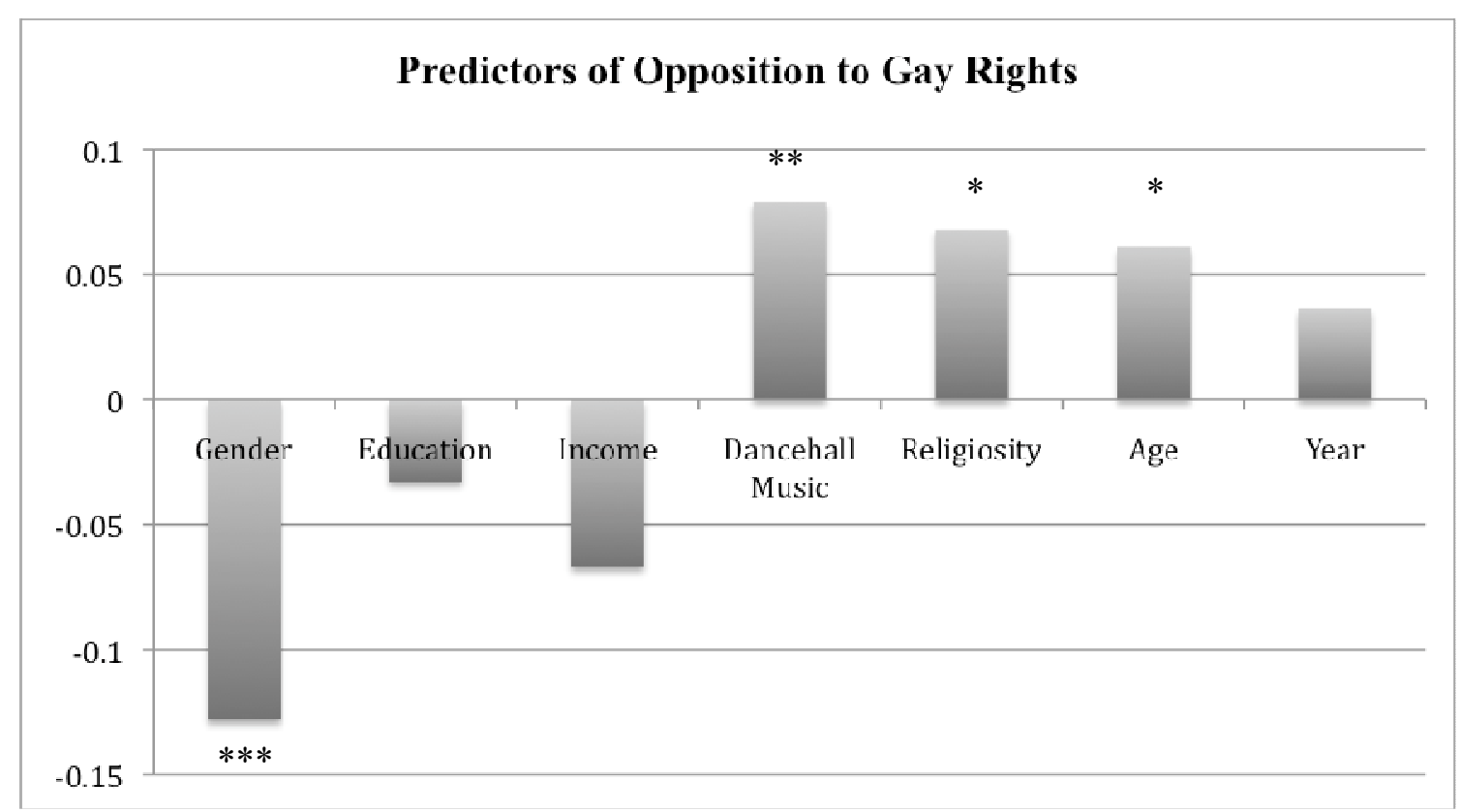

Figure 4

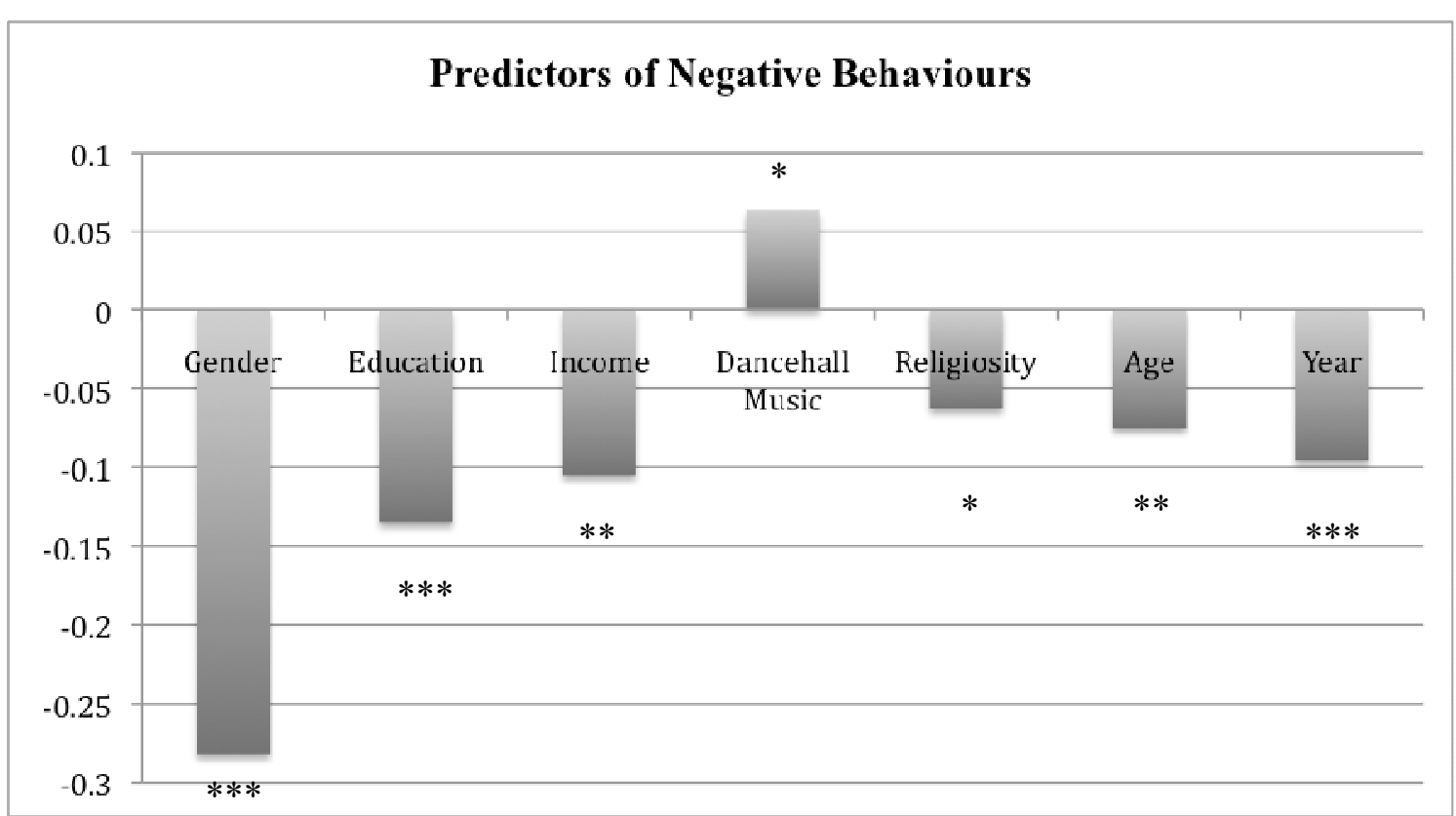


Predictors of anti-gay prejudice 28

Figure 5:

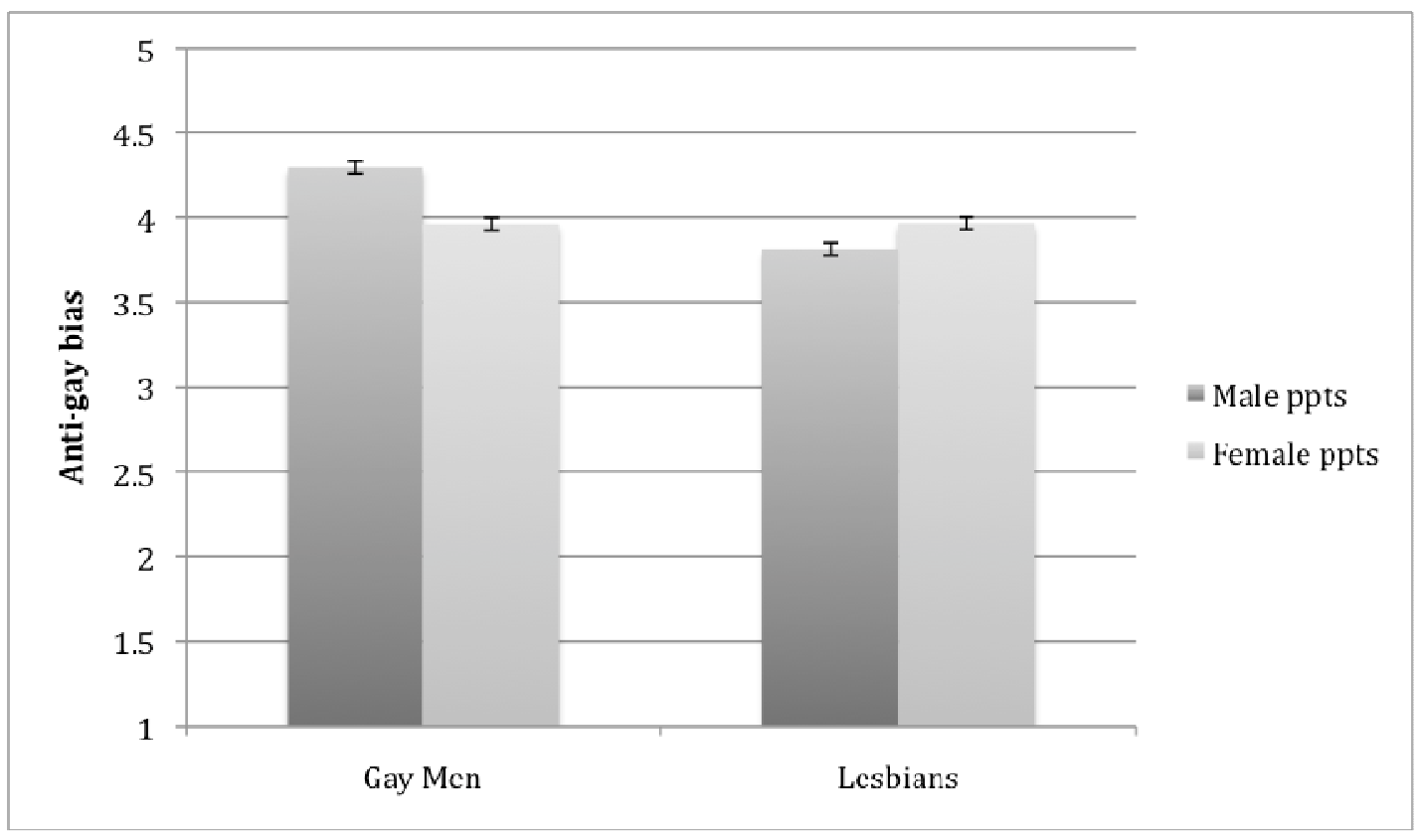




\title{
Footnotes
}

\begin{abstract}
${ }^{1}$ On April 1, 20131 US dollar was worth approximately 99.17 Jamaican dollars and 1 British pound was worth approximately 152.15 Jamaican dollars.

${ }^{2}$ Because these were the only three gender-specific questions, we used these three questions as our measure of anti-gay prejudice despite acknowledging that each of the three questions measured a different component of anti-gay prejudice. Analyses using each of the items individually yielded very similar results.
\end{abstract}

